\title{
Canadian Association of Gastroenterology Visiting Research Professorship and Visiting Clinical Professorship
}

\author{
Francois Boudreau PhD, VP Research Affairs, Kevin Waschke MD, VP Education Affairs
}

\section{CAG VISITING RESEARCH PROFESSORSHIP}

The Canadian Association of Gastroenterology (CAG) Visiting Research Professorship is offered annually to a member of the CAG who is a proven teacher and an outstanding researcher. The Visiting Research Professor is asked to visit at least six sites (typically academic centres) across the country during the period of July 1st to June 30th. The CAG supports the cost of the air travel for the Visiting Research Professor while the host sites are responsible for costs of local travel, accommodation, meals, and any honorarium.

\section{Announcing the 2015-2016 CAG Visiting Research Professor -} Dr Jan Huizinga

Dr Jan Huizinga graduated from the University of Groningen (the Netherlands) with degrees in physiology, pharmacology and biochemistry. After post-doctoral training at the University of Toronto, he was recruited by McMaster University. He was director of the Intestinal Diseases Research Program at McMaster from 2005-2008. He is now director of the Honours Biology Pharmacology Coop program, a thriving undergraduate program training the next generation of pharmacologists. He is senior editor for Frontiers in Neurosciences. He went on a sabbatical in 2012-13 at Renmin Hospital of Wuhan University in China, where he instituted high-resolution colonic manometry and conducted a clinical study on patients with chronic constipation for which he received an honorary professorship at Wuhan University Health Sciences.

Dr Huizinga has won Research Excellence Awards from the Pharmacological Society of Canada and the CAG. A highlight was the 3rd International Janssen Award from the International Neurogastroenterology and Motility Society. He has been nominated for the 2016 Cannon Award in Physiology from the American Physiological Society.

Dr Huizinga's research focus is to understand control mechanisms of gastrointestinal motility in health and disease. His laboratory has achieved excellence in understanding the role of interstitial cells of Cajal (ICC) as pacemaker cells controlling gut motility. Web of Science lists 264 publications with an h index of 47, with publications in Nature, Nature Medicine and Nature Communications. The three major goals of the Huizinga laboratory are to understand the mechanistic relationships between motor patterns, motor functions and the activities of ICC and the enteric nervous system; to provide guidelines for the study of colonic motility in patients using high-resolution manometry and to unravel the pathophysiology of idiopathic chronic constipation and intestinal pseudo-obstruction.

\section{Thanks to the 2014-2015 CAG Visiting Research Professor -} Dr Paul Moayyedi, McMaster University

The CAG would like to express its sincere appreciation to Dr Moayyedi for being the 2014-2015 CAG Visiting Research Professor. Dr Moayyedi visited six centres during his term (Winnipeg, Toronto [twice], Edmonton, Halifax and Quebec City). This is a remarkable commitment and accomplishment. Our congratulations and thanks to Dr Moayyedi.

\section{CAG VISITING CLINICAL PROFESSORSHIP}

The CAG Visiting Clinical Professorship, introduced in 2012, is offered annually to a member of the CAG who is a proven educator and an outstanding clinician with interest in clinical research.The Visiting Clinical Professors will focus on community/regional meetings and events as a priority, over academic sites. The recipient of the award is asked to visit at least six centres across Canada during the period of July 1st to June 30th. The CAG supports the cost of the air travel for the Visiting Clinical Professor while the host sites are responsible for expenses related to local travel, accommodation, meals, and any honorarium.

Announcing the 2015-2016 CAG Visiting Clinical Professor Dr Anne Griffiths

Dr Anne Griffiths is a pediatric gastroenterologist at SickKids Hospital, Toronto; Co-Lead of the SickKids Inflammatory Bowel Disease (IBD) Centre; the inaugural holder of the Northbridge Chair in IBD; and Professor of Pediatrics at the University of Toronto. Pediatric IBD is her clinical and clinical/translational research focus. She is the Principal Investigator of the Canadian Children IBD network: a joint partnership of the CH.I.L.D. Foundation and CIHR. This Network brings together 12 academic pediatric IBD programs nationally. She is Deputy-Chair of the Executive Committee of the Crohn's and Colitis Canada (CCC) Gene, environment, microbe (GEM) study.

Dr Griffiths has been on the steering committees of all major industry-sponsored clinical trials and registries of biologic therapies in pediatric Crohn's disease and ulcerative colitis (UC). She was the principal investigator on the development of the outcome measures for pediatric ulcerative UC (PUCAI) and disease-specific health-related quality of life in pediatric IBD (IMPACT questionnaire). She has authored over 200 peer reviewed publications and over 40 book chapters, and has lectured widely internationally on pediatric IBD.

Thanks to the 2014-2015 CAG Visiting Clinical Professor Dr Chris Andrews, University of Calgary

The CAG would like to express its sincere appreciation to Dr Andrews for being the 2014-2015 CAG Visiting Clinical Professor. Dr Andrews visited seven centres during his term (London, Ottawa, Hamilton, Toronto, St John's, Kelowna, and Halifax). This is a remarkable commitment and accomplishment. Our congratulations and thanks to Dr Andrews.

If you are interested in having Dr Huizinga or Dr Griffiths visit your centre during their term, please contact the CAG National Office at general@cag-acg.org.

Nominations for these awards can be made by any member of the CAG. To nominate a candidate please complete the nomination form for these awards found on the CAG website at www.cag-acg.org under 'Recent Listings'. A curriculum vitae must be concurrently forwarded to the CAG National Office, preferably in electronic format. The CAG Research Committee will review the nominations for the Visiting Research Professor and the CAG Education Committee will review the nominations for the Visiting Clinical Professor; each will make recommendations to the CAG Board, who will make the final decision on the recipients. Nominations for these awards must be received by July 31, 2015.

The CAG is proud to acknowledge its Benefactor Corporate Sponsors:

AbbVie Corporation

Pentax Canada Inc
Actavis Specialty Pharmaceuticals Co

Janssen Inc
Olympus Canada Inc

Takeda Canada Inc 


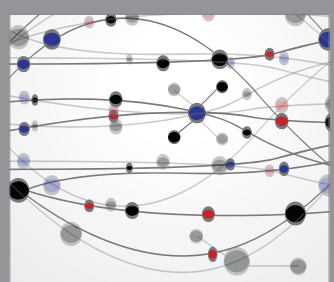

The Scientific World Journal
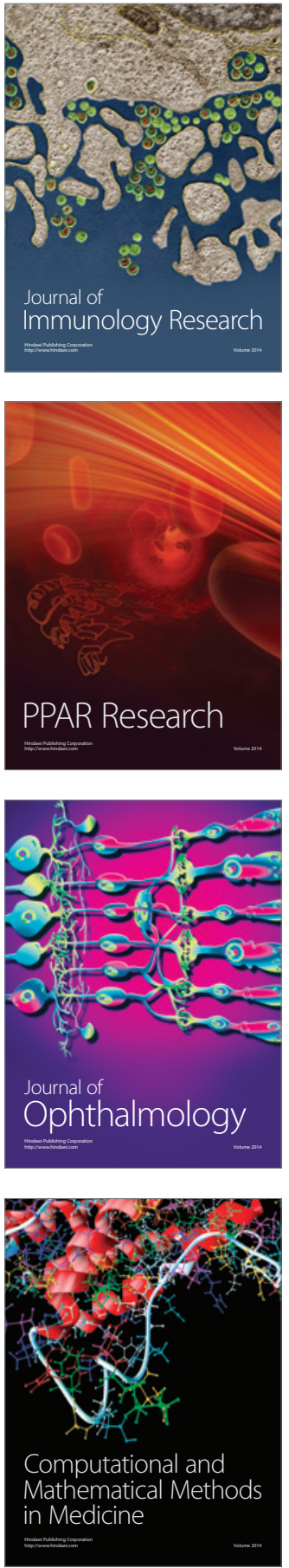

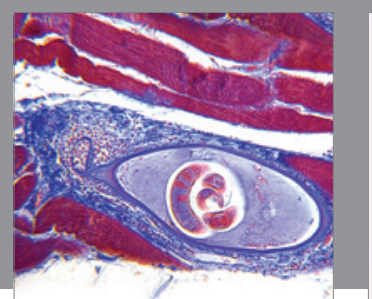

Gastroenterology Research and Practice

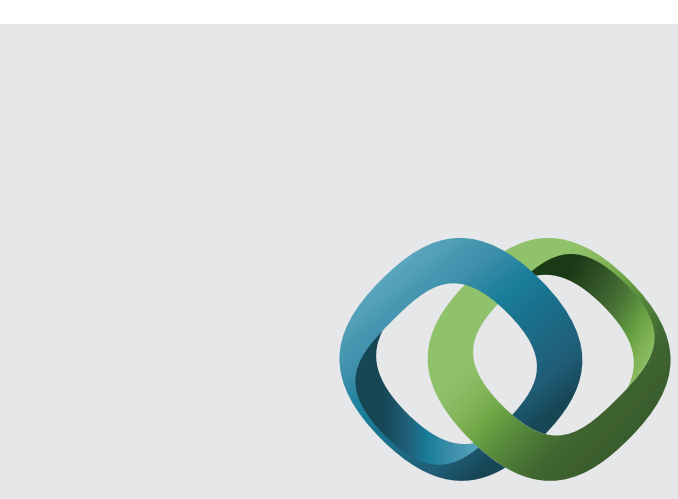

\section{Hindawi}

Submit your manuscripts at

http://www.hindawi.com
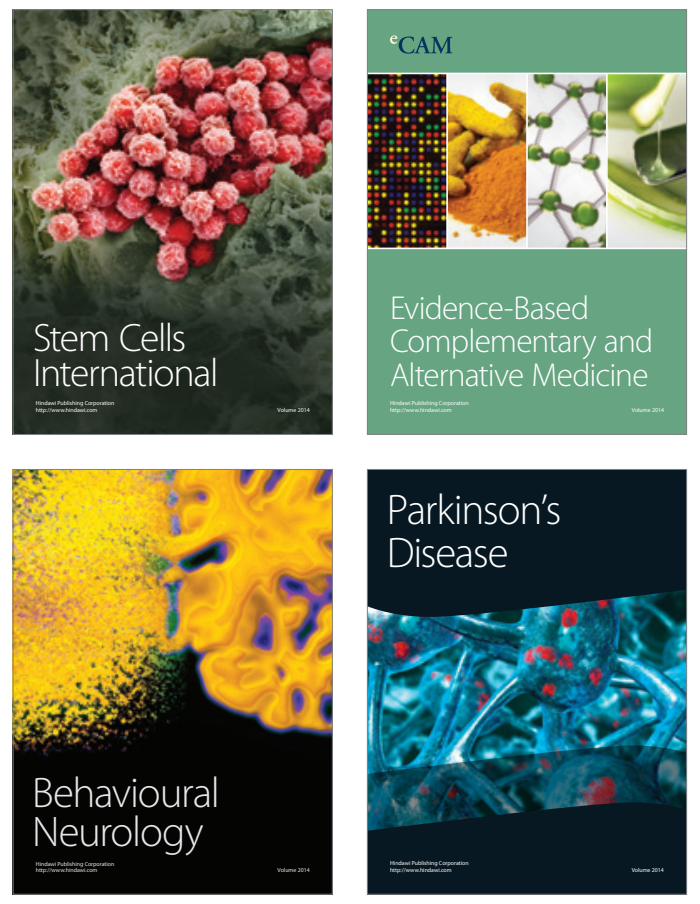
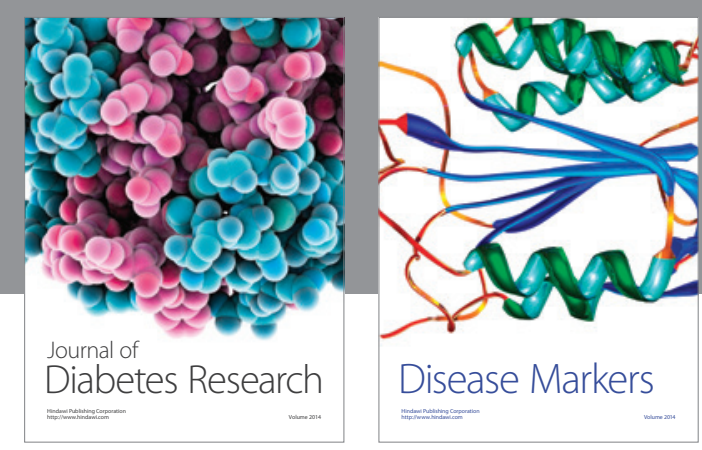

Disease Markers
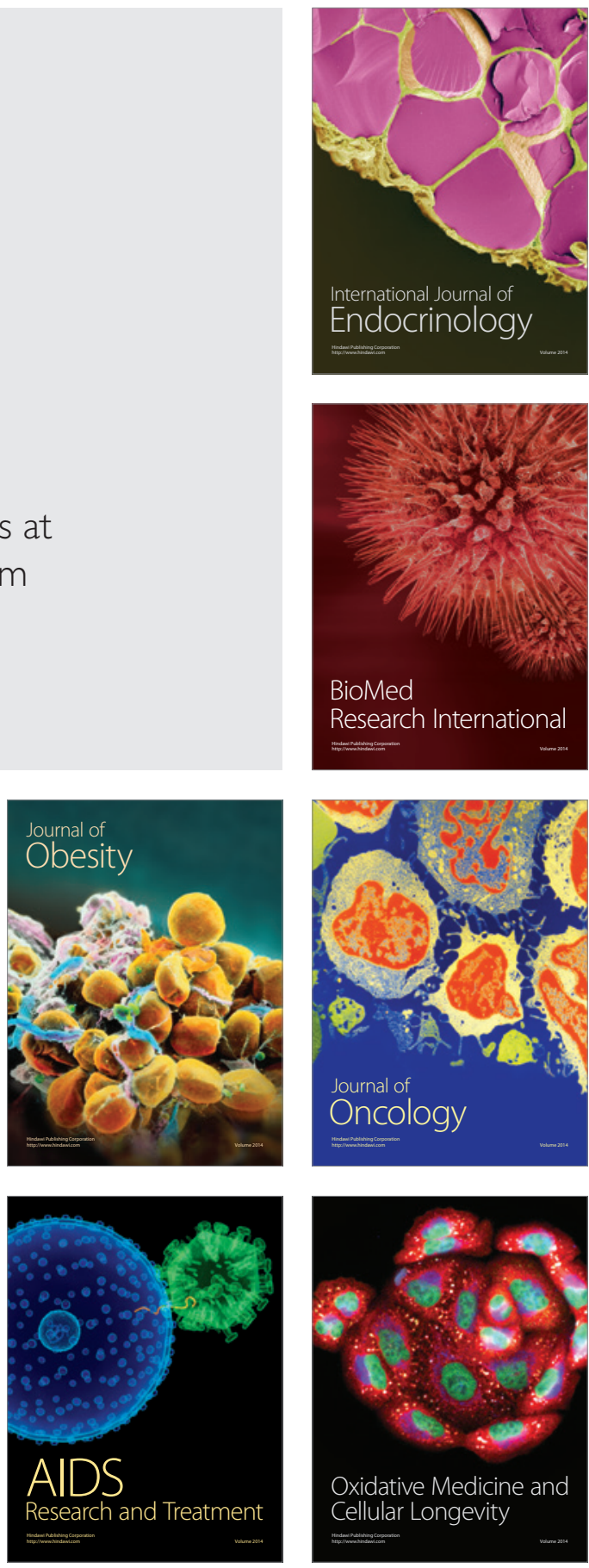